\title{
Cuerpo privado, imagen pública: el autorretrato en la práctica de la fotografía digital
}

\author{
Private Body, Public Image: \\ Self-Portrait in the Practice of Digital Photography
}

\author{
Elisenda Ardévol y Edgar Gómez-Cruz \\ Internet Interdisciplinary Institute \\ Universitat Oberta de Catalunya. Barcelona
}

\section{RESUMEN}

El artículo propone una reflexión sobre el autorretrato como práctica cada vez más extendida en Internet, no sólo para la presentación del usuario en los contextos sociales de interacción, como las fotos que acompañan el perfil personal en las redes sociales, sino también como práctica creativa, lúdica o auto-reflexiva sobre sí, el cuerpo y la identidad personal. Para algunos autores, la práctica del autorretrato está relacionada con formas de control y empoderamiento, especialmente en el realizado por mujeres, mientras que para otros se trata de la popularización de la exploración de la identidad personal antes circunscrita prácticamente al ámbito de la experimentación y expresión artística, o bien puede entenderse desde una perspectiva psicológica, como una práctica terapéutica de transformación personal. En todo caso, esta práctica de autorretrato íntimo, vinculada generalmente a la narrativa cotidiana personal pasa a ser, a través de internet, una práctica pública que puede tener una amplia audiencia y destinada a la interacción social. En este sentido, podría entenderse también como una nueva forma cultural de presentación social de sí que conllevaría un trabajo de performación de la identidad personal de un modo relacional, ya sea como una actuación pública del yo o como resultado de una práctica performativa sobre el propio cuerpo.

Palabras clave: Prácticas mediáticas, Imagen corporal, Persona, Internet, Cultura digital.

\section{SUMMARY}

This paper show some thoughts about the self-portrait as an extended practice on the Internet, not only as a representation of users of Social Network Sites (profile pictures for example) but also as a creative and playful self-reflective practice on the self, the body and the personal identity. To some authors, the practice of self-portraits is related to control forms and empowerment, in particular, the self-portraits made by women. For other authors, it seems to be the popularisation of a practice previously reserved to artists, 
while others point to the therapeutic and personal transformation powers of the selfportrait. What seems to be undoubted is the relationship between the self-portrait and the everyday narratives of the self and, on the Internet, this personal and intimate practice becomes public and even creates an audience. In this sense, the self-portrait could be understood as a new cultural form of self-presentation that could be understood as both, the public performance of the personal identity and the result of a performative practice with the own body.

Key words: Media Practices, Body Image, Self, Internet, Digital Culture.

\section{INTRODUCCIÓN}

Nadie es tan guapo como parece en su fotografia de perfil en Facebook, ni tan feo como la foto de su carnet de identidad.

(Sara, en Facebook)

El artículo propone una reflexión sobre el autorretrato como práctica cada vez más extendida en Internet, no sólo para la presentación de los usuarios y usuarias en los contextos sociales de interacción, como las fotos que acompañan el perfil personal en las redes sociales, sino también como práctica creativa, lúdica o auto-reflexiva sobre el propio cuerpo y la imagen corporal. Nuestro objetivo es explorar desde una perspectiva antropológica, la relación de la persona con las imágenes que realiza de sí misma, y que decide hacer circular en Internet, a partir de un trabajo de campo etnográfico sobre las prácticas de la fotografía digital y su imbricación en la vida cotidiana.

Para ello partiremos de la experiencia de ambos investigadores en el estudio de la sociabilidad y la cultura digital, desde el análisis de la identidad personal en chats y foros de discusión (Ardévol y Vayreda 2003; GómezCruz 2003), hasta el estudio de la presentación del cuerpo en sitios web de contactos (Enguix y Ardévol 2010; Gómez-Cruz 2008). Concretamente, nos preguntaremos cuál es la relación que establece la persona con sus imágenes en y a través de las tecnologías digitales, refiriéndonos específicamente a la producción, circulación y consumo para y en Internet de una imagen muy particular, el autorretrato.

Tomaremos como eje de la discusión los datos obtenidos en un conjunto de entrevistas realizadas por Gómez-Cruz durante su trabajo de campo sobre las prácticas de la fotografía digital en Flickr y otras redes sociales. Dicha etnografía se realizó con un grupo de fotógrafos y fotógrafas amateurs entre septiembre de 2008 y marzo de 2010 y constituyó parte de su tesis doctoral (Gómez-Cruz 2011). Dado que el grupo se constituía a través 
de la plataforma flickr.com, se realizó una observación participante también del sitio web donde los autorretratos emergieron como una de las principales prácticas de fotografía digital, explorando otras plataformas digitales y realizando entrevistas en profundidad sobre esta práctica. Aquí analizaremos particularmente cinco entrevistas - más algunas intervenciones puntuales en foros de discusión- que tienen como característica común haber sido realizadas a mujeres que hacen del autorretrato una práctica intensiva en Internet, y que constituyen una mirada muy particular sobre nuestro objeto de estudio con la cual pretendemos dialogar.

Consideramos que el autorretrato en la fotografía digital se configura como una práctica cultural popular distinta al autorretrato artístico, aunque mantiene conexiones con éste, y que su estudio puede ser útil para iluminar algunos aspectos de la constitución de la identidad personal y la presentación social del cuerpo. Partimos de la idea de que las prácticas con las imágenes de sí son prácticas reflexivas que contienen un potencial transformador. Como afirma Don Slater:

La cámara, como una herramienta de representación activa y masiva, es un vehículo para documentar las condiciones propias (de vida, trabajo y socialidad); para crear representaciones alternativas de uno mismo, de su sexo, clase, grupo de edad, raza, etc. y de ganar poder (y el poder de análisis y alfabetización visual) sobre la imagen personal (Slater 1999: 290).

Para algunos autores, el autorretrato digital es la popularización de la exploración de la identidad personal, antes circunscrita prácticamente al ámbito de la experimentación y expresión artística (Avgitidou 2003). Para otros, la práctica del autorretrato está relacionada con formas de control y empoderamiento, especialmente en el realizado por mujeres, que pasan de objetos pasivos de la mirada masculina a sujetos activos en el control de su imagen corporal (Lee 2005). Finalmente, otros autores y autoras lo entienden desde una perspectiva psicológica y experiencial, con efectos terapéuticos, es decir, transformadores de la experiencia individual (Martin y Spence 2003). Pero ¿cómo suceden estas "transformaciones"? Nuestro interés es pues averiguar a partir de los relatos de las mujeres entrevistadas, si éstas experimentan este poder transformador de las imágenes, qué valor dan a esta práctica y qué papel juega la mediación tecnológica y el hecho de exponer públicamente en Internet sus autorretratos.

\section{LA PRÁCTICA DE LA FOTOGRAFÍA DIGITAL}

La antigua preocupación sobre la fotografía y sus prácticas cotidianas ha 
retomado aire a raíz de los nuevos dispositivos digitales y desde propuestas que proponen la aparición de una nueva ontología de la fotografía (Lister 1997; Mitchell 1998; Ritchin 2008; Fontcuberta 2010) como parte de una nueva "revolución tecnológica" (Ritchin, Dietz y Reid 1999). Para la mayoría de estos autores, lo que parece claro es que «el rol y la función de la fotografía digital occidental parece haber cambiado sustancialmente" (Van Dijck 2008: 58), cuestión en la que coinciden, entre otros, especialistas como Okabe e Ito (2003) y Koskinen (2004, 2005 y 2007). La fotografía digital parece tener otros tiempos, objetos y procesos que la fotografía analógica, es decir, conjugar distintas prácticas. Entre ellas, una de las más comunes y extendidas, es la de tomarse fotos a uno o una misma. Los autorretratos cada vez se integran más como parte de la cotidianeidad y ya no resulta extraño ver a alguien tomarse una foto con el brazo extendido y en internet pueden contarse por millares las imágenes en las que aparece una o más personas tomándose una foto frente a un espejo (Fontcuberta, 2010), práctica que, sobre todo, parece aún mucho más común entre los jóvenes (Tinkler 2008; Livingstone 2008).

Para aproximarnos a la práctica del autorretrato en la fotografía digital, ésta debe entenderse en el contexto de su imbricación con las tecnologías digitales de comunicación, como Internet y la telefonía móvil (Thompson 1998). La fotografía digital está transformando no solo el campo cultural de la fotografía - por ejemplo, difuminando la división entre la práctica profesional, amateur y casera-, sino la misma forma en que la gente se fotografía y utiliza las fotografías. La fotografía como práctica popular, ha pasado de ser una práctica ritual, que se realiza en momentos y contextos específicos, como testimonio y objeto de memoria — eventos familiares, celebraciones, viajes-, a una costumbre cotidiana que puede darse en cualquier momento del día e independientemente de la ocasión. Todo se ha convertido en fotografiable. Pero los cambios no se han dado sólo en el terreno de los contextos de producción y de los objetos fotográficos, sino también en lo que hace referencia a los contextos de circulación y exhibición de las imágenes, concretamente en su utilización como objetos de sociabilidad. En la vida diaria, la función social de la fotografía digital no es sólo la de preservar la memoria familiar o personal, sino también la de actuar como vínculo social mismo, es decir, como un elemento importante en la producción social y mantenimiento de la unidad familiar, del grupo de amigos, o de la pareja.

Tinkler nos dice que las imágenes mismas pueden ser entendidas por los investigadores y por los propios actores sociales como medios para establecer y representar conexiones; como por ejemplo, establecer quién es un miembro de una comunidad particular. Así, quien está o no está en la foto es un aspecto relevante en la constitución del grupo social, del mismo 
modo que las narrativas que acompañan los álbumes familiares o las fotos de viaje o de una cena con los amigos. Mostrar las fotografías también forma parte de la sociabilidad del grupo y de la actualización de los lazos sociales, así como la circulación de estas imágenes dentro del grupo, mediante su intercambio o regalo (Tinkler 2008: 261). Estas funciones sociales de la fotografía analógica, propias de la cultura Kodak, denominada así por Richard Chalfen (1987), se mantienen en la fotografía digital, pero la manera en la que se llevan a cabo y las prácticas que las acompañan se han modificado y ampliado sustancialmente.

Estas transformaciones se deben, en primer lugar, a la presencia constante de la cámara digital como dispositivo de uso cotidiano, gracias en gran parte, pero no sólo, a la incorporación de una cámara en la gran mayoría de los teléfonos móviles que se venden en la actualidad. Esto hace que la cámara fotográfica haya pasado a ser un dispositivo personal, frente al objeto material que representaba en la era analógica. En segundo lugar, tomar una fotografía digital es fácil, rápido y barato; hacerla circular en Internet, también. Internet posibilita que la imagen personal y casera se inserte en circuitos de distribución más amplios que los del ámbito doméstico, en ámbitos de exhibición pública que anteriormente solían estar reservados a los círculos profesionales, o en contextos que directamente antes no existían, como el caso de las llamadas redes sociales. Esto tiene al menos, dos cuestiones a tener en cuenta en la relación que establecemos con nuestras imágenes. La primera tiene que ver precisamente con las nuevas formas de sociabilidad mediada por las tecnologías informacionales. En las redes sociales como Facebook o Tuenti, la función conectiva y social de la fotografía resulta mucho más importante que su función como objeto de memoria personal. La fotografía en estos nuevos espacios sociales es fundamental en la presentación de la persona y un elemento clave de la interacción social. En este contexto, la imagen que ofrecemos sobre nosotros mismos, y especialmente la imagen corporal, pasa de ser un reflejo de nosotros mismos a ser parte consustancial de cómo somos ante los demás. Y es en este contexto donde el autorretrato toma un especial relieve.

La segunda cuestión tiene que ver con las características específicas de Internet como medio de comunicación. Muchas de las imágenes personales y familiares son subidas a plataformas abiertas de libre compartición. Aunque en muchos casos se suben a estas plataformas fotografías personales para ser compartidas por un grupo de amigos o familiares, lo cierto es que estas plataformas proporcionan la opción de que puedan hacerse públicas, y generalmente, por comodidad, suelen mantenerse en abierto, aunque sean para uso privado. ¿Hasta qué punto estas imágenes caseras son "públicas"? ¿Cómo se define lo público y lo privado en Internet? 
En otros casos, y relacionado con la cuestión anterior, las fotos se suben a plataformas específicas como Flickr o Fotolog para compartirlas con una amplia audiencia, ya sea para recibir comentarios de otras personas sobre la fotografía, ya sea para establecer nuevas redes sociales a partir de las propias fotografías, ya sea para mostrar a la gente nuestra manera de mirar. Las personas que suelen hacerlo con regularidad se constituyen como una comunidad de práctica (cf. Wenger 1999) con otras personas que quieren compartir sus fotografías y aprender de los demás. En estos contextos, la misma producción de fotografías está orientada a su exhibición en Internet; es decir, se fotografía para compartir las imágenes, de manera que todo el proceso de producción y el propio objeto fotográfico solo se entiende a partir de su contexto de exhibición, circulación e intercambio. En este caso, el autorretrato se constituye como un género fotográfico popular y hay cientos de grupos en estas plataformas dedicados específicamente a este género. En este sentido, la imagen de sí - y en especial el autorretrato- puede tratarse como un objeto de consumo e intercambio, además de tornarse espectáculo para una amplia audiencia; lo que algunos autores han asociado con la espectacularización de la intimidad (Sibilia 2009).

En todo caso, la práctica del autorretrato, reservada generalmente a la práctica artística, o bien vinculada a la esfera privada, íntima y personal, pasa a ser a través de internet, una práctica común y pública, es decir, realizada para la interacción social y destinada a una amplia audiencia. En este sentido, podría entenderse también como una nueva forma cultural de presentación social de sí (Goffman 1959) que conllevaría un trabajo de performación de la identidad individual de un modo relacional, en el cual la imagen del propio cuerpo se tornaría fundamental, pero no en el sentido definido por Butler de actos de cuerpo (Butler 1993), sino que es la imagen corporal - tomada literalmente- la que deviene un agente en la performación de la identidad. Performatividad de la imagen corporal que puede vehicularse, como veremos, con una práctica erótica (Bianciotti 2011).

Aunque hay trabajos previos que señalan este carácter "performativo" de la imagen como representación (Cf. Holm 2008), la propuesta que planteamos aquí sobre el autorretrato como imagen corporal (imágenes del propio cuerpo) es que el objeto fotográfico se constituye como un acto performativo que dota de sentido a la persona, al cuerpo y a la interacción con los demás, en un proceso continuo que es previo al acto fotográfico y que no se termina con éste, sino que fluye con las prácticas que se desprenden de su uso, especialmente las relacionadas con internet y las redes sociales (Tabachnik 2007). Por lo que respecta a la práctica en concreto que veremos a continuación, el autorretrato no (sólo) (re)presenta a la persona, la constituye y objetiva; es decir, hace presente al sujeto en la comunica- 
ción mediada tecnológicamente. Frosh plantea que en el contexto de internet, "la fotografía es entendida no como una mera tecnología de representación visual sino como un tipo de acción (visible) constituida dentro de un mundo social" (Frosh 2001: 43). Explorando esta propuesta, entenderemos a la fotografía y el objeto de representación desde la práctica y no exclusivamente desde la estética o la semiótica de la imagen (Cf. Gómez y Ardèvol 2011).

La aproximación teórico-metodológica a la fotografía digital como práctica supone descentrar la representación como unidad de análisis, para examinar los procesos materiales e inmateriales que intersectan y constituyen el objeto fotográfico. Se trata entonces de entender la práctica fotográfica digital como un conjunto de prácticas interrelacionadas que van desde la producción del objeto (la elección del momento, la intención del sujeto, la cámara, el trípode, la ropa, el posado, el cuerpo de la persona, la luz, etc.) hasta su exhibición y uso (en Facebook, Flickr, amistades, comentarios, enlaces, respuestas, archivo, copia, etc.). El objeto fotográfico se constituye como tal a partir de estas complejas redes sociotécnicas de las cuales forma parte. Las entrevistas que hemos realizado se han basado precisamente en "historias de prácticas" (Gómez-Cruz 2011) en que las personas explican su propia relación con sus prácticas fotográficas y con los distintos componentes que les dan sentido — personas, objetos, cámaras, expectativas, sentimientos, relaciones, técnicas, fotos, programas informáticos, sitios web, etc. - , siendo el autorretrato una práctica central en el caso de las entrevistas seleccionadas para este texto.

\section{EL AUTORRETRATO COMO IMAGEN CORPORAL}

Los autorretratos no son necesariamente una práctica nueva en la fotografía, ni por supuesto, en la pintura. Los autorretratos, como los retratos, han sido sin lugar a dudas, uno de los principales objetos fotográficos (Cf. Martínez-Artero 2004). Entendemos por autorretrato fotográfico aquellas imágenes en las cuales el autor y el modelo representado son la misma persona; es decir, el sujeto se reconoce como autor material de la fotografía y como objeto representado. Diríamos que el sujeto establece con lo representado no solo una relación de semejanza - la figura "se parece a mí»—, sino también de identidad —el que sale en la foto "soy yo"—, y además de agencia causal — «a he tomado yo»—, y así es también reconocido por los demás. El caso del autorretrato utilizando una superficie refrectante —un espejo o similar - es muy frecuente en la fotografía digital y tiene muchos seguidores y practicantes. Se trata de un tipo de autorretrato particu- 
lar, conocido en la red como egoshots, o reflectogramas según Fontcuberta (2011), en el cual se da la circunstancia, además, que no solo la persona productora es objetivada en la fotografía, sino también el proceso de producción mismo. En otras palabras, la fotografía muestra no solo al sujeto que toma la foto, sino al sujeto en el momento de disparar la cámara; en el acto mismo de tomar la fotografía. Justamente en este movimiento es donde la imagen corporal se constituye como objeto de la práctica fotográfica, creándola en la misma acción de representarla (Cf. Dalton, Lee, Goicolea y Brown 2000).

Sostenemos que, en el autorretrato, el cuerpo actúa como mediador entre la persona y su imagen de sí; es decir, la persona se reconoce en la imagen de su cuerpo. De manera que la identidad personal y de género es en gran parte actuada a partir de la imagen corporal que construimos de nosotros y de nosotras mismas. La importancia de la imagen corporal como mediadora en la constitución de la persona como sujeto social ha sido ya tratada por distintos autores clásicos y contemporáneos (Lévy-Bruhl 1985; Thomas y Ahmed 2004; Featherstone 2010). Como señala Mari Luz Esteban para gran parte de nuestros modelos culturales actuales:

Desde la visión actual dominante, el cuerpo — considerado como sede de la razón, las experiencias y las emociones- es puesto en relación con la construcción social del concepto de persona, la formación del "yo". Por tanto, se reconoce su papel conformador de la subjetividad de las personas como seres individuales y sociales. En este marco, la imagen corporal y el cuerpo individual y social son fundamentales en la construcción de la propia identidad y pertenencia a los diferentes grupos (Esteban 2004: 69).

Y siguiendo a otros teóricos del cuerpo social como Le Breton (2002), Esteban sugiere además que en la sociedad de consumo en la que vivimos, "muchas de las identidades corporales que se venden como 'ideales' suelen venir definidas de antemano, envasadas y ya dispuestas para el público desde las industrias de consumo", justamente a través de las imágenes de la publicidad (Esteban 2004: 69). De manera que nuestra persona se identifica con nuestra imagen corporal y, a su vez, nuestra imagen corporal se constituye en gran parte a partir de este repertorio disponible que proviene de los medios de comunicación. El cuerpo es pues moldeado socialmente y constituido conforme a estas imágenes «ideales" que actúan como patrones culturales normativos; como lo que debe ser un "buen cuerpo".

En relación a la imagen fotográfica, Featherstone afirma asimismo que "la grabación de la cara y el cuerpo por la cámara a través de la fotografía se vuelve la forma dominante para representar la imagen corporal y también para imaginar la imagen del propio cuerpo" (2010: 194). 
La relación entre cuerpo y persona parece estar bien establecida en nuestras sociedades y de una forma inequívoca. La identidad personal de cada uno y de cada una está estrechamente vinculada a su cuerpo, de manera que la persona y su cuerpo son indisociables, nacen y mueren juntos. En el contexto de esta normalidad cultural, los límites de la persona están claramente determinados por los límites corporales, como ya sugería Lévy-Bruhl a principios del siglo pasado:

Cada uno de nosotros cree saber exactamente de qué se compone su individualidad personal y dónde se sitúa el límite. Mis sentimientos, mis pensamientos, mis recuerdos, eso soy yo. Mi cabeza, mis brazos, mis piernas, mis órganos internos, etc., eso también soy yo. Todo el resto de lo que yo percibo no soy yo. Mi individualidad está de ese modo aprehendida por mi consciencia y circunscrita por la superficie de mi cuerpo y yo creo que la de mi vecino es justamente como la mía" (Lévy-Bruhl 1985: 95).

Así establecemos nuestra noción de persona como individuo con capacidad de libre albedrío y responsabilidad moral. Sin embargo, no deberíamos dar por sentado que esta concepción sea universal, sino que debemos suponer, desde una perspectiva antropológica, que la forma en que aprehendemos nuestros límites corporales como límites de nuestra individualidad se produce durante el proceso de enculturación, y que la forma de sentir y entender eso que llamamos cuerpo, persona e identidad personal está cultural e históricamente situada. También deberíamos considerar que en nuestras propias sociedades éstos no son conceptos estáticos y unívocos, sino dinámicos y sometidos a una gran variabilidad interpretativa, vividos de una manera emocional diversa y juzgados moralmente de una forma plural. De manera que la experiencia de la individualidad no se detiene siempre ni necesariamente en la periferia del cuerpo. Las fronteras son imprecisas, mal determinadas e incluso variables de persona a persona. Se defina como se defina nuestra relación con la imagen corporal, en cualquier sociedad, esta relación es dinámica, sujeta a cambios y transformaciones, nunca es fija.

El aprendizaje de las técnicas culturales y de cuál es la relación adecuada con nuestra imagen corporal o cómo debemos presentar públicamente nuestro cuerpo también varía según ciertas categorías de ordenación social, como en nuestras sociedades pueden ser el grupo étnico, la nacionalidad, la clase, el género o la edad. Es decir, el cuerpo es el eje central de la constitución de nuestra identidad personal, en especial la de género, y de nuestras diferencias como actores sociales, pero la imagen del cuerpo es moldeable y modificable y por tanto, cómo el cuerpo es exhibido y representado en el espacio público, es una cuestión de control social, pero también de negociación y de resistencia. 
Si bien es cierto que la normatividad cultural viene encapsulada a través de los medios de comunicación de masas, también debemos tener en cuenta la agencia de las personas en su vida cotidiana como productoras de imágenes. Aunque muchas de las imágenes se basan en estas normatividades expuestas por la publicidad, también se realizan parodias y se trazan alternativas, resistentes, transgresoras o inquietantes. Estas imágenes no profesionales, actualmente, no se circunscriben al ámbito privado, sino que se comparten a escala mundial a través de la red. La imagen privada se convierte en imagen pública, compitiendo con las imágenes producidas por las industrias culturales y los medios de comunicación, que a veces, también las toman prestadas.

La práctica generalizada del autorretrato en la fotografía digital responde a distintas motivaciones, pero en todo caso, no es solo una forma de representar y reflejar nuestro cuerpo, sino también y ante todo, una forma de imaginar nuestra propia imagen corporal y de performar mediante estas imágenes nuestra identidad personal y social, de un modo dinámico, inacabado..., aunque sea siguiendo el imperativo cultural de nuestra sociedad de consumo, donde la identidad corporal se constituye como un proyecto personal nunca cerrado (Giddens 1991).

Coleman, retomando a Deleuze y Guattari, propone justamente entender que la relación con las imágenes genera cuerpos. Es decir, desde una posición deleuziana, se entendería al cuerpo "no como un sujeto circunscrito que está separado de las imágenes sino que lo vería como la conexión entre humanos e imágenes como constituyendo un cuerpo" (Coleman 2008: 168). Dicho de otra manera, nuestra experiencia del cuerpo es a través de la imagen. De esta manera, refiriéndose a las imágenes de las adolescentes que participaron en su estudio, Coleman escribe: "Las imágenes fotográficas son un tipo específico de imagen que produce conocimientos particulares, entendimientos y experiencias de sus cuerpos" (Coleman 2008: 170).

A continuación exploraremos cómo las mujeres entrevistadas entienden la realización de autorretratos como una práctica creativa (aunque no se consideren ni artistas ni fotógrafas) que ha supuesto un control sobre su imagen, y que experimentan como acompañada de una sensación de «iberación", que en muchos casos, ha conllevado también un resultado terapéutico — ayudándolas a superar ciertos momentos difíciles de su vida—, y que además, han incorporado esta práctica en su vida cotidiana como forma de interacción social y como metáfora de su propia manera de ser en el mundo. La práctica de la fotografía digital, para estas mujeres, ha supuesto una forma de tomar el control no sólo sobre su imagen corporal, sino sobre sus vidas en otros ámbitos de la experiencia. 


\section{EL AUTORRETRATO DIGITAL COMO EMPODERAMIENTO}

Como hemos dicho antes, la práctica del autorretrato ha sido tradicionalmente reservada, y sigue siendo común, a los artistas. Aunque, curiosamente, muchas de las mujeres que han tenido éxito en este campo han practicado la técnica del autorretrato intensivamente; fotógrafas como Jo Spence y Cindy Sherman construyeron su carrera artística teniendo a los autorretratos como su principal motivo. Avgitidou sugiere que el autorretrato fotográfico se ha utilizado, no tanto como una forma de representación, sino como una forma de exploración de sí:

Los artistas adoptaron esta idea y continuaron produciendo autorretratos que exploraban, actuaban o performaban su ser. No puede resultar inesperado que los artistas que más incorporaron este género de autorretratos vinieran de grupos "marginalizados": mujeres, gays y lesbianas. Los autorretratos eran una herramienta primaria para la visibilidad política, una declaración visual de "yo existo". Los autorretratos probaron ser el medio perfecto de la exploración de una identidad social y culturalmente estereotipada, una declaración y una celebración del ser. Los artistas se apropiaron de su imagen estereotipada y la usaron en trabajos artísticos para subvertir sus significados (Avgitidou 2003: 133).

Laura Mulvey, en su pionero análisis sobre la narrativa en el cine - y ampliamente citado como base para muchos estudios sobre imagen e identidad-, utiliza la teoría psicoanalítica "como un arma política" para, desde una posición feminista, desentrañar el orden patriarcal. El cine, plantea, "como un avanzado sistema de representación, nos lleva a preguntarnos sobre las formas en las que el inconsciente (formado por el orden dominante) estructura formas de ver y placeres en mirar" (Mulvey 1975: 7). Cuestión que ha sido también planteada por otros autores para el campo del arte pictórico, como Berger, quien afirmaba que: "los hombres actúan, las mujeres posan (appear). Los hombres miran a las mujeres. Las mujeres se ven a sí mismas siendo miradas. Esto determina no sólo la mayoría de las relaciones entre hombres y mujeres sino también la relación de las mujeres consigo mismas" (Berger 1972: 41). Las relaciones de género heterosexuales parecen tener su piedra de toque en este acto de mirar y ser mirada, donde la mujer se constituye como objeto del deseo masculino y, por extensión, su cuerpo es lo que la hace femenina; mientras que en el hombre es su actitud, su mirada, lo que es constitutivo de su masculinidad. En este sentido, situarse al otro lado de la cámara, como sujeto que mira, y representarse a sí mismas siendo ellas el objeto de su propia mirada, se puede considerar en sí mismo como un acto de 
empoderamiento y de rebeldía. La mujer se constituye en el mismo acto de ser mirada... por ella misma.

Lee, en su trabajo sobre móviles y mujeres en Corea, afirma que se está generando una "cultura femenina de la cámara móvil" (Lee 2005) y con ello se refiere al hecho de que el teléfono móvil ha sido apropiado por parte de las mujeres de una manera importante, convirtiéndose además en un puente hacia el uso de otras tecnologías tradicionalmente relacionadas con el género masculino, cuestión que parece compartir Hjorth (2006). Estudios con resultados similares se han elaborado en varios países: Taiwan (Wang 2009), Suecia (Palmgren 2009) o Israel (Schwarz 2010). Pero no se trata sólo de compartir imágenes "entre mujeres" y crear una nueva cultura femenina, sino de lanzarlas a la esfera pública, de devolver la mirada a la mirada masculina.

La práctica del autorretrato como forma de experimentación y de empoderamiento adquiere su máximo sentido cuando éste es expuesto a la mirada pública. Es decir, no se trata solo de verse a sí misma ante el espejo, sino de exponer esa mirada frente a los demás; este es el acto de poder, la práctica cuyo efecto quizás pueda ser transgresivo y transformador de pautas culturales; aunque también supone un reto y un riesgo para la persona que expone su propia imagen de sí.

En los relatos de nuestras entrevistadas ${ }^{1}$, cuando se les pregunta sobre cómo inician su práctica de autorretratarse y de compartir estas imágenes públicamente en Internet, reconocen que dan este paso como una forma de ganar control sobre su imagen y sobre sí mismas. Jessa y Emma son interesantes de citar aquí porque ambas tienen una imagen corporal opuesta. Jessa "no se gusta" y autorretratarse es una forma de trabajar su propia imagen corporal como vía de aceptación de su cuerpo, mientras Emma, se sabe fotogénica y empieza a hacer autorretratos para Internet como una forma de demostrarse que no necesita de la mirada masculina para sentirse bien con ella misma, que su cuerpo sigue siendo bello a través de su mirada.

Jessa:

Siempre me sentí cero fotogénica cuando empecé con la foto, siempre sentía que no habían capturado lo que yo quería expresar o que posiblemente yo tenía muy

${ }^{1}$ Las entrevistas se han realizado utilizando distintos formatos; entrevistas grabadas en audio, entrevistas realizadas por correo electrónico, por mensajería instantánea o a través de foros de discusión. Para este texto las presentamos en un formato unificado. Por ejemplo, aunque hemos conservado algunas de las expresiones propias de la comunicación mediada por ordenador, como el uso de emoticones en el caso de entrevistas por chat, se ha utilizado las grafías propias de la escritura del castellano estándar para facilitar su lectura. Los nombres que aparecen han sido modificados. 
claro lo que quería y no me supe explicar, así que para no caer mal... imejor me la tomo yo!

Emma:

Fue bastante dolorosa la ruptura con mi novio [fotógrafo], de hecho era más que eso, pues vivimos juntos por más de 2 años, así que bueno ya te imaginarás, él era antes quien me tomaba fotos y de cierta manera las primeras fotos que puse en el Flickr fue como un "yo puedo sola tomar fotos"... parece tonto y me siento un poco tonta escribiendo esto... pero ahora que lo preguntas y que lo pienso con la cabeza más fría... fue algo así...en realidad yo sólo quería demostrarme a mí misma que era capaz de sacarlas y después me gustó hacerlo y continué... [...] Creo que el cuerpo es algo muy bonito y tengo la fortuna (modestia aparte) de tener un cuerpo que se ve bonito en las fotos.

\section{DESNUDARSE ANTE UNA AUDIENCIA}

Las mujeres entrevistadas ${ }^{2}$ entienden la práctica del autorretrato como una forma de experimentación personal, se divierten con ello, y aunque no se consideran artistas, ni muchas de ellas fotógrafas, entienden que lo que hacen se asemeja a una práctica artística, especialmente cuando posan desnudas. Entienden que el fotografiar su cuerpo forma parte de un proyecto personal de descubrirse a sí mismas, de mostrarse tal y como son; un acto de autenticidad. Según Gemma San Cornelio:

El autorretrato muchas veces funciona como el refugio que permite al artista, extraer y mostrar elementos de sí mismo expresamente para él mismo [...]. Al igual que a Rembrandt el uso de disfraces ha inspirado a muchos artistas a la trasformación, es un aspecto que se repite en la práctica del autorretrato, y tiene que ver con la alineación, estilización y adopción de un rol. Es el propio artista que se muestra escondido tras diferentes personalidades, identificándose con idealizados parangones o interpretando un papel, tal vez sin nada que ver con él (San Cornelio 2008: 80).

Nuestras autorretratistas siguen este mismo principio expresivo, posan para sí mismas, a veces, adoptando distintos roles y personajes. El destinatario primero de sus autorretratos son ellas mismas, aunque cuando "quedan bien", los comparten con su público, los exponen en su sitio web. Construyen en Internet un espacio personal; su perfil en una red social

\footnotetext{
${ }^{2}$ La selección de entrevistas que aquí se presenta no quiere ser una muestra representativa de un colectivo particular de mujeres, sino que lo que se analiza es la significación de determinada práctica con la imagen. No obstante, cabe apuntar que se trata de mujeres jóvenes profesionales que tienen alrededor de los 30 años y que pertenecen a distintas comunidades en el contexto español y latinoamericano.
} 
dedicada a la fotografía se constituye, a la vez, en su propia galería de exhibición y en su propio laboratorio de trabajo personal.

Zeta:

El principal motivo por el que hay fotos mías en mi Flickr es porque yo lo he convertido en un rincón muy personal. Esta no es mi tarjeta de presentación como fotógrafa, va un poco más allá: es mi modo de desestresarme, es aquí donde yo vomito mi día a día, por así decirlo. En tanto que es personal, en muchas ocasiones soy yo la que aparece. Porque es muy complicado y no siempre me interesa conseguir que una modelo exprese lo que yo siento o lo que me apetece transmitir. Además es complicado encontrar una modelo a altas horas de la madrugada, que es cuando suele llegarme la inspiración para determinadas fotografías... Supongo que también tiene parte de aceptación personal. Atreverse a retratarse y atreverse a exponerse en un sitio como Flickr es un método de aceptación personal, sin complejos, te muestras.... Lo que yo publico es parte inevitable de mi persona, desde los atardeceres o las cucharas de las tazas, hasta la piel que aparece.

Sofía:

Hago fotos de desnudos porque me encantan, es la forma más linda que se puede mostrar una fotografía, mostrarte como eres, porque me gusta mostrarme como soy. Aunque el pudor también me gana. El complejo con mi cuerpo. Eso me hace hacer encuadres solo de mi parte superior. [...] Los desnudos los pongo en Flickr y no en el Fotolog, porque allí pasa mucha gente que los ve como morbo y no como arte.

Tiara:

Trabajar con el cuerpo no es un tema fácil; sobre todo si eres mujer. Porque comienzas a plantearte cuántas de aquellas visitas son personas que realmente valoran la poética de las imágenes y cuantas te escriben de pajeras, me sorprendió porque jamás pensé que tendría tantas visitas. [...] La mirada sexuada es una consecuencia que asumo desde el momento en que decido empelotarme frente al lente.

Vivi:

El desnudo siempre fue un tema fotográfico, es normal que también esté en la web. Creo que hay mujeres que refuerzan su identidad mostrándose desnudas en la web. Desnudarse es morboso. La pregunta es si eso les ayuda a ir a playas nudistas, o a quitarse la ropa sin problema delante de extraños, o si es justamente por eso que solo se desnudan en la web. O si les da igual y lo hacen por amor a la belleza [...] o yo que sé.

Atreverse a mostrarse desnudas es para la mayoría de mujeres entrevistadas dar un paso hacia delante; supone una forma de mostrarse a sí mismas, y ante los demás, tal y como son; o tal vez, tal y como quieren ser o como quieren ser miradas. Entienden que supone una dosis de "morbo" para la audiencia pero la rechazan, decididas a no dejarse tragar por cierta mi- 
rada masculina... Desafían el pudor personal como parte de un proceso de experimentación poética, artística y erótica; un juego que puede llegar a ser sexual, pero es "su" imagen y tienen el control sobre ella, sobre lo que quieren mostrar, cuando y de qué modo. El rechazo de estas mujeres a la mirada "morbosa", "sexuada" o "pajera" es prácticamente unánime, aunque todas dicen que no la pueden evitar, y en su mayoría reconocen que, especialmente cuando muestran imágenes de desnudos, aumenta espectacularmente el número de visitas masculinas. Se establece entonces con ellos dos tipos de relación: la complicidad o el rechazo y el ostracismo. Ellas deciden.

Emma:

Por supuesto, por el contenido de mis fotos no falta el pervertido que comenta o envía algún mensaje fuera de tono... pero como bien diría mi madre uusted se lo buscó!n así que lo bloqueo y trato de ignorar el asunto... me agrada que la mayoría de mis contactos sean hombres, hay hombres insoportables, pero algunos se toman el trabajo de ver las fotos y de detectar en ellas cosas interesantes, detalles que no cualquiera se da cuenta... [...] la palabra "fan" la odio... pero debo aceptar que algunos se comportan como tal... y bueno, me divierte...

Como hemos visto, ellas saben que su público masculino aumenta cuando exponen autorretratos o posan desnudas; no les importa, incluso les divierte... si no molestan demasiado, e incluso hacen buenos amigos o buscan precisamente cierto tipo de complicidad con ellos. Algunas explican cómo les ha costado dar el paso de hacer y subir las fotos, cómo el sentido del pudor no las ha abandonado, pero sienten que el esfuerzo ha merecido la pena. Este esfuerzo no es solo "vencer complejos", sino un trabajo de producción de la imagen de sí que quieren mostrar en público, imagen que implica muchas veces hacer cientos de fotografías hasta dar con la que les satisface. Del público esperan reconocimiento a su trabajo y también aprender de sus comentarios, desde los que les señalan posibles mejoras técnicas, a los que les aportan nuevos motivos para su actividad creadora. Las mujeres entrevistadas buscan el diálogo con la mirada masculina, más que suscitar el deseo sexual o mostrar sus encantos para la seducción.

Emma:

No me interesa pertenecer a grupos de fotos porno, porque no quisiera que mis fotos fueran consideradas de ese tipo. [...] en realidad uno no puede hacer nada para que alguien no piense en este tipo de cosas... la gente puede pensar lo que se le antoja y ya... solo que no estoy interesada en participar en ese tipo de grupos $[. .$.$] y ya... resuelvo bloquearlas. Un chico me preguntó que si mis fotos eran$ una invitación a conocerme... yo le dije que a través de mis fotos se me podría conocer un poco... pero que mi intención no era tenerme como un catálogo de productos, para que pidiera la Emma que más le gustaba... que yo ni siquiera 
me llamaba así... por supuesto que se pueden generar malos entendidos... pero si la gente quiere pensar que lo que estoy haciendo es como una "venta" de mí, pues que lo piense... habrá quien disfrute las fotos sin tanta tontería.

La mayoría afirma que les gusta recibir visitas, y modestia aparte, el reconocimiento público y su éxito como fotógrafas y modelos conlleva cierta dosis de vanidad. Aunque no siempre se reconozca, el éxito de sus imágenes, que éstas tengan muchas visitas y comentarios, que se puntúen como favoritas, que las enlacen, genera cierto orgullo personal por su obra y cierto compromiso con su público.

Jessa:

Yo sí me tomo fotos por ego y vanidad!!! (lo confieso =S ) jejeje me gusta tomarme fotos tengo muchísimas, mmm en Flickr no tengo muchas pero en otros espacios como hi5 o myspace sí... y sí, lo hago definitivamente por vanidad!!!... cuando estoy sola y creo que es un momento para un auto retrato creo que hago como 50 tomas... ja y hasta que no tengo una o varias que me gusten no estoy tranquila así me puede llevar 5 horas...

El público que llega a las páginas, su audiencia, es heterogénea, pero buscan complicidades en su proyecto personal. Especialmente complicidades con el género masculino, que consisten en compartir conocimientos técnicos sobre fotografía, y que pueden llegar a relaciones personales y de amistad. No hacen fotos para tener éxito social como "chicas guapas", hacen fotos para sí mismas y para compartirlas con quien las valore. En este sentido, no hacen fotos pensando en o para satisfacer a la audiencia, pero tienen una audiencia -y mayormente masculina. Lo saben, les gusta, la cuidan (respondiendo a sus comentarios, comentando o agregando las fotos a sus favoritas) y la seleccionan (agregando o bloqueando las propuestas de contacto).

Emma:

Casi nunca respondo a los comments que me hacen porque creo que se vuelve en un eterno poner "gracias" porque qué más se puede decir... solo con ciertas personas se genera un pequeño diálogo... pero las respuestas prefiero darlas en mensajes individuales... no soy muy fan de las comunicaciones masivas... [...] no tomo fotos para mi público, no para el público en general, quizás sí he tomado fotos y sobre todo publicado en determinado momento pensando en alguien [...] no es que haya tomado la foto para él, se podría decir que la tomé siguiendo una idea de él... algunas fotos han sido tomadas para amigos... pero no me he descubierto tomando una foto con el objetivo de gustar al grueso del público...

Sofía:

La mayoría, diría el 90\% que tienen fotolog, tratan de subir fotos solo de la persona a beneficio que te digan palabras bonitas, es una forma de subir más el ego, yo ahora ocupo fotolog más para comunicarme con mis amigos que no es- 
tán cerca de mí, me gusta que me critiquen mis fotos pero en fotolog no se da eso [...] el flickr lo veo como mostrar los trabajos que haces, las cosas que te apasionan, que te den ideas de nuevas fotografías, compartir conocimientos. Los amigos que tengo a través de flickr me criticaban mis fotos, me daban consejos [...] pero en fotolog solo sacan fotos para verse bien, para obtener la mayor cantidad de comentarios y visitas...

Asun:

En fotolog [...] se dedican a subir fotos chorras y a postear como posesos buscando tener un millón de posts, como si eso significara que son mejores personas o algo [...] la intención es conseguir tener muchos posts en los que alaben sus "domingas" [...] y los tíos se hacen fotos sin camisetas y tal [...] yo te posteo y te digo lo buena que estás para que tu me postees y me digas lo bueno que estoy, pues eso acaba en un vacío enorme, como todos los círculos viciosos. Lo que busco en una foto es que sea bella, que sea original, que sea creativa. En resumen, que llame la atención. Que en un mural de cien fotos la mía sea una de las que te paras a mirar. Es un poco vanidoso, la verdad, pero eso es en principio lo que busco. Muchas veces no sé si hago fotos por mí, porque me gusta, o para los demás, para que les guste al resto.

Tiara:

[...] las respuestas a los comentarios comencé a hacerlo por deferencia y por agradecimiento y respeto. Si alguien se toma el tiempo para comentar una foto, qué te cuesta a ti dar las gracias por ello, luego fue armándose un diálogo que me permitió ir aprendiendo [...] sentir que lo que muestro vale la pena para otros. Yo siento que incluso los comentarios de tus contactos son fundamentales para aguzar el ojo y darte cuenta de tus debilidades y fortalezas [...] como aquella tercera persona que observando desde fuera siempre representará otro punto de vista, que tú no vislumbraste al momento de la captura.

Su relación con el público es compleja. No se trata de exponer el cuerpo para conseguir un público fiel o convertirse en una microcelebridad - aunque algunas podría considerarse que lo son y que les gusta serlo-, para estas autoras, este no es un fin en sí mismo; se trataría de una falsa autoestima, precisamente porque solo buscarían complacer la mirada masculina.

Asun:

A mí en principio no me disgustan los desnudos, ni el erotismo, al contrario (en mis fotos se ve), pero cuando veo una foto de una chica que lo que hace es exponer sus encantos para que a unos cuantos chicos les caiga la baba algo se me revuelve por dentro, no sé, me incomoda [me da la impresión] de que la intención es la de conseguir muchos posts y luego esos posts son los que sostienen la poca seguridad que tienen en sí mismas...

Por ello insisten en distinguir sus autorretratos de aquellos que buscan atraer el deseo de otro cuerpo. No quieren ser miradas, quieren ser vistas. No quieren que se consideren sus imágenes como objeto de deseo, quie- 
ren que se las aprecie como sujeto creador de deseos; que el público aprecie su trabajo fotográfico. Son, en todo caso, creadoras de imágenes deseantes y deseosas. Lo importante, para ellas, es trabajar su relación con su cuerpo y su sexualidad de una forma creativa, a través de sus imágenes, pero también buscan el reconocimiento público de su trabajo; les interesa conocer cómo estas imágenes corporales son vistas y comentadas por su público.

INTIMIDAD Y ESPACIO SOCIAL

Es interesante detenerse en cómo estas mujeres entienden flickr como un espacio social específico, distinto a otros sitios de Internet que también utilizan. Cada lugar en la red tiene sus especificidades como espacio social y sirve para unas esferas de relación u otras. El espacio como concepto relacional, físico o virtual, está siempre socialmente producido a partir de los objetos y de los diferentes actores que los movilizan y les dan sentido (Harvey 2006). El espacio social está definido por distintos grados de copresencia, proximidad y reciprocidad: ver y ser visto, reconocerse o ignorarse. Las cuestiones de publicidad y privacidad deben entenderse entonces como distintas formas de modular las relaciones sociales de inclusión y exclusión, distancia y proximidad, simetría y asimetría en las obligaciones recíprocas que pueden ser materializadas en distintos términos y disposiciones, espaciales o no. Como ya se ha dicho, flickr es para ellas un laboratorio y una galería; su lugar de trabajo y también el lugar de exposición y exhibición de su obra creativa. Está abierto a todos, visitantes y amigos. De modo que en el mismo "espacio" se establecen distintos grados de socialidad, de relación con el público que accede al sitio: desde el absoluto desconocido al amigo íntimo, el novio, etc. Así, pueden dar a conocer el sitio a sus amigos y amigas, y en la interacción con su público, se crean nuevas amistades, que llegan a conocerse en persona, pero como dicen ellas mismas, no es lo mismo una foto en facebook, el fotolog o en flickr.

Si bien los autorretratos son imágenes que ellas realizan y que se exponen públicamente en internet, las mujeres entrevistadas buscan insertarse en redes de sentido determinadas (arte, expresión) y evitan otras (la pornografía, la "tía buena") que están en muchas ocasiones determinadas por ciertos convencionalismos sociales. No quieren seducir mostrando su cuerpo a través de la imagen corporal; buscan, en todo caso, que sus autorretratos seduzcan por sí mismos; que sus imágenes corporales objetivadas en la fotografía, seduzcan. De esta forma, la relación de las personas con su intimidad sigue otros caminos que una clara distinción entre público y privado. 
Vivi:

Para mi las fotos públicas son las que están en la web y las privadas las que no??? Jejeje. No, no es cierto. Hay fotos públicas que son privadas, aunque no sé si privadas es la palabra adecuada. Creo que para mí al menos, las fotos privadas son aquellas que son un poquito más espejo que las demás... no sé, muestran algo. [...] A ver, hay fotos que me incomoda un poco subir, pero las subo, no sé porqué. Luego me acostumbro a verlas.

\section{Emma:}

No me siento vulnerada en mi intimidad por las fotos de desnudos, en cambio, hay ciertas cosas que hablan mucho más de mí... como por ejemplo el libro en que apoyo el pie... [...] en fin... tonterías que solo yo me percato...

Jessa:

No me da pena ni inseguridad "desnudarme" ante mí, además de que, si no me gusta, la borro y tomo otra.

Según Ben-Ze'ev (2003:451), la intimidad es una relación emocional asociada con el grado de apertura y proximidad que en cierta medida se opone a la privacidad. Estar emocionalmente próximo a alguien significa abrirse a ese alguien, y por tanto una pérdida de privacidad. Salvaguardar la privacidad consiste en mantener ciertas cosas o cuestiones de una misma para una misma. En el caso de nuestras mujeres entrevistadas, intimidad y privacidad están en estrecha relación. Hay cosas íntimas que no queremos compartir. Por ejemplo, Emma no se siente "vulnerada en su intimidad" por mostrar imágenes de su cuerpo públicamente en Internet, porque su «intimidad" no es visible para alguien que no la conozca. No está en su cuerpo, sino en los detalles que ella elije y que "dicen más de ella" sin que sea de una forma explícita. Para Vivi, la foto "privada" es aquella que se hace para los amigos y conocidos, que son una imagen "espejo"; de manera que hay fotos públicas que son "privadas".

La intimidad es una forma de cercanía, de ausencia de distancia, y por tanto, la mayor parte de las autoras de autorretratos digitales entrevistadas no exponen cosas "íntimas" en sus cuentas de una forma abierta. Cuando la imagen de sí, ya sea del cuerpo desnudo o no, se considera demasiado personal o íntima, las fotos no suelen mostrarse en abierto.

Luli:

Me gusta mucho tomarme [fotos] desnuda... me encanta mi cuerpo, pero no las publicaría, porque esas son sólo para mí... me daría pena publicarlas, repito esas son sólo para mí, para mi ego muy personal.

Emma:

Tengo un muy buen amigo al que le envío fotos que no pongo en flickr... pero son por el contrario fotos más íntimas pero más cubiertas... jajajaja... más como de una serie que hice y que a veces no quiero poner porque son muy personales... 
Cuando ponen una distancia personal, es cuando la imagen corporal no es considerada como un "reflejo", sino como una extensión de su personalidad o, más bien, un trabajo creativo sobre su imagen corporal, que puede hacerse pública sin entrar en excesiva contradicción con su sentido del pudor. La línea es tenue. "Me gusta mostrarme como soy", dice Sofía, pero a la vez afirma que cuando posa para ella, la que posa no es ella, al menos "no es ella en su esencia". Su "esencia" está como repartida entre el sujeto que toma la foto, la modelo y la fotografía final. Es decir, la modelo, la que posa, se disfraza, se transforma, hace parodias, experimenta... es otra que la que toma la foto, de tal manera que incluso los que la conocen personalmente no la reconocen en la fotografía.

Vivi:

Me sorprendía que no me reconocieran, me pareció divertido que en fotos pudiera resultar tan polifacética.

Emma:

Las fotos de Emma son para mí casi como las fotos de un personaje (sin que vayas a pensar que tengo problemas de personalidades múltiples) en todo caso, los desnudos son de ella... no creo que sea lo mismo ver una mujer en una foto a verla personalmente, incluso mucha gente que me conoce y que me ha visto no puede creer que sea yo la que aparece en las fotos.

Patty:

A mí por ejemplo normalmente me gusta fingir que soy otra persona, me encanta salir en fotos y que no se me reconozca.

Una manera de poner distancia entre su cuerpo y su imagen corporal es la construcción de un personaje. Ese personaje puede actuar como un doble. No se trata de esconderse en el anonimato; aunque utilicen disfraces, se muestran "tal como son" y no ocultan sus rostros. Aunque no las reconozcan, son reconocibles. Sin embargo, sí es cierto que en su mayoría no ofrecen sus datos privados. Suelen utilizar los convencionalismos mismos de internet para crearse una identidad virtual que actúa como mediadora por interposición; de alguna manera, este cuasi-anonimato a través de la creación de un alias o personaje, las protege de contactos indeseados.

Emma:

Supongo que habrá conocidos que les parezca que está mal lo que hago... pero la verdad me importa muy poco su opinión [...] pienso en lo que podría pensar alguien que me conozca y que no sepa que hago este tipo de fotos... creo que también tendría que entrar a explicar qué hace viendo fotos de desnudos, ¿no? No sé... es algo muy personal que no considero que tenga que explicar a nadie... alguna vez tuve que responderle a mi madre ante su pregunta de si era yo la que aparecía en una foto desnuda que era una postal de invitación a una ex- 
posición [cuando era modelo] y pues le dije que sí... se escandalizó un poco pero ya pasó... y si no escandalizo a mi madre...

Hemos visto que desnudarse tiene que ver con el pudor corporal y que está relacionado con nociones de privacidad e intimidad que pueden variar enormemente de un contexto cultural a otro, así como de una persona a otra o de una situación a otra dentro de un mismo entorno cultural. La normatividad sobre el pudor corporal femenino puede manifestarse en sentirse objeto de una reprobación moral, como nos cuenta Emma, o como nos dice Sofía, mediante su etiquetaje social como "esa loca que se empelota tomándose fotos a sí misma", o también a través de comentarios "de mal gusto" o directamente, en invitaciones sexuales explícitas.

La imagen corporal que se expone es pública, pero el cuerpo es privado. La imagen pública que presentan no pretende ser un fiel espejo de sí mismas; y, aunque pretenden ser ellas mismas, no buscan en el autorretrato un "efecto espejo". Al menos no siempre ni necesariamente. Vivi es tajante en eso: "las fotos hechas con espejo muestran al fotógrafo y no son autorretratos. Quiero decir que fijan una forma de mirar o de sentirse en un momento dado, es como si uno se viera de fuera con una lupa...". Esta afirmación puede parecer desconcertante. ¿Por qué el reflectograma destruye el efecto que busca? Parece como si la presencia del sujeto en el objeto destruyera el encantamiento de la imagen corporal. La foto, el autorretrato, dejaría de ser una imagen corporal para ser, simplemente, un reflejo de la persona.

\section{LA RELACIÓN DE LA FOTOGRAFÍA CON LA VIDA}

Mari Luz Esteban (2004) utiliza el concepto de itinerarios corporales para dar cuenta de los procesos de autotransformación personal a través de determinadas prácticas que tienen que ver con la modificación del cuerpo (modelos, culturistas, etc.). En los casos analizados también encontramos que la práctica de la fotografía ha supuesto para estas personas algo más que un simple bobbie o afición. Para algunas, la fotografía ha cambiado su relación con la imagen que tenían de sí mismas, aprendiendo a aceptar su cuerpo "tal y como es". Para otras, la fotografía es una forma de relacionarse con el mundo que han hecho cotidiana — una mirada fotográfica. De distintas maneras o por distintas vías, para ellas la práctica fotográfica se convierte en una forma de mejoramiento personal. Una tecnología del yo (Foucault 1996), pero no como disciplinamiento del cuerpo para adaptarlo a una imagen ideal, sino como un trabajo sobre la imagen para cambiar su 
percepción del cuerpo. Por ejemplo, sobre una foto en la que aparecen sus piernas desnudas y en primer plano, titulada "odio mis piernas", Martita dice: "Es como las odio porque no me gustan, pero también pueden quedar bien en una foto, tengo que aprender a quererlas también... tengo que aceptarme como soy".

Ellas establecen un paralelismo entre su modo de fotografiar y su modo de ser, de manera que, mejorando la técnica fotográfica, mejoran también su forma de estar en el mundo y viceversa.

Asun:

Para mí la fotografía es un juego de experimentación [...] para llegar a hacer buenas fotos tengo que aprender. [...] Me conviene equivocarme y por eso las subí [aquellas fotografías] a disgusto sabiendo que no eran perfectas. Claro que eso de buscar la perfección y esconder lo que no está medido y limado y perfeccionado es el cuento de mi vida y también en mi vida pienso últimamente que lo que me conviene es equivocarme y aprender, y también en mi vida, como en la fotografía, me cuesta (psicología barata, jejeje) [...] la fotografía es como una pequeña puesta en escena de mis contradicciones. [...] Yo en mis inicios fotográficos, hace dos años o así, usaba el photoshop a todo lo que daba. Cogía una foto y le metía filtros, bordes, añadidos, color, de todo, vamos. Y luego personalmente me pasaba algo así, yo me cogía a mí misma y me ocultaba detrás de la imagen que quería dar a los demás, igual que ocultaba la foto detrás de los filtros del photoshop. Más tarde me he ido desescondiendo, y poco a poco, he ido también utilizando menos photoshop en mis fotos... [...]

Clara:

Al menos para mí, la foto va acompañada de procesos biográficos también. Y lo que viví hasta diciembre coincide con lo que mostré en las fotografías hasta esa fecha [...] la existencia de un "otro" excesivamente celoso, desde ahí comencé a atreverme más con las imágenes, tanto en el momento de capturarlas como de subirlas.

Asun:

La fotografía se adapta a mí por ser más rápida, menos trabajosa, por darme menos oportunidad de ser tiquismiquis. [...] En la fotografía disparas y cataplof, ya está, no hay más tu tía. Y eso es lo que busco yo también ahora a nivel personal: no corregirme, disparar y cataplof.

Vivi:

La fotografía es terapéutica [...] todos aquellos autorretratos me ayudaron a construirme una identidad en Internet... y fue demasiado divertido.

Su experimentación con la imagen corporal no puede comprenderse como aparte o disociada de su experimentación con la técnica fotográfica, y todo ello forma parte de un proyecto vital, de un trabajo sobre sí y sobre sus relaciones con los hombres, y por tanto — qué duda cabe- tam- 
bién se trata de un trabajo sobre su identidad de género. Cómo esto se produce es complicado de explicar. Por una parte, ella se constituye como sujeto de una práctica técnica — la fotografía - y como objeto de esa práctica - el cuerpo fotografiado- creando lo que hemos denominado una imagen-cuerpo. Esta imagen-cuerpo se proyecta en un espacio social de proximidad mediada, donde la interacción social se organiza, precisamente, a partir de la circulación de las imágenes en un espacio social definido como público y privado - galería y estudio o taller. Hemos visto que la imagencuerpo que se presenta no suele ser un mero reflejo del cuerpo de su creadora, sino, diríamos, una versión mejorada - un cuerpo idealizado (o no) en el cual la creadora inscribe sus deseos, reflexiones y aspiraciones (o temores). Esta versión mejorada o reflejo extendido del cuerpo actúa como mediador en la relación interpersonal. La idea es que este reflejo extendido juegue a favor de su creadora en un doble sentido: que el público aprecie la imagen-cuerpo, no solo por la belleza del cuerpo representado, sino también por la pericia técnica y/o calidad expresiva de su creadora. Es decir, se reconozca a la mujer que es ella como sujeto agente y no solo - aunque también- como objeto de deseo. Esta imagen-cuerpo se convierte así en una extensión de la persona, forma parte de su agencia y de lo que la persona quiere ser para el otro.

\section{CONCLUSIONES}

Hemos entendido el autorretrato como una forma cultural cuyos referentes provienen del campo artístico y que se vinculan tradicionalmente con procesos de autoconocimiento y de experimentación personal. Sin embargo, con la popularización de las tecnologías digitales de la imagen, parece integrarse en la vida cotidiana de muchas personas, con distintas funciones y usos. Concretamente, hemos analizado el autorretrato como una práctica; es decir, no lo hemos considerado desde una perspectiva formal o estética, sino como una práctica específica de la fotografía digital. Hemos contemplado su contexto concreto de producción, de circulación y de exhibición, y entendido la práctica de la fotografía digital como una práctica de producción cultural que está inserta en una red socio-técnica más amplia que incluye los nuevos espacios sociales que abre Internet. Además, esperamos haber mostrado que el autorretrato, como práctica paradigmática de la fotografía digital, resulta tremendamente útil para discutir cuestiones más amplias sobre cómo comprendemos la relación entre la persona, el cuerpo, la imagen y las identidades de género (Cf. Di Próspero 2011). 
Para centrar el análisis, hemos dialogado con un grupo de mujeres que, por una razón u otra, han hecho del autorretrato una práctica constante en su vida cotidiana, de manera que, al menos durante un tiempo, lo han llevado a cabo de forma intensiva y apasionada. A través de sus reflexiones sobre su práctica, hemos generalizado un posible modelo que, de alguna manera, amplía e incluso cuestiona algunas de las preconcepciones que teníamos sobre el autorretrato como reflejo de la persona. La relación de estas mujeres con sus imágenes, y especialmente con sus imágenes corporales, es sutil. No es la imagen la que media entre ellas y su cuerpo, sino que su cuerpo se constituye en mediación entre ellas y sus imágenes de sí. Como hemos intentado explicar, no modifican su cuerpo para adaptarlo a una imagen corporal deseada (como lo haría una cirugía estética), sino que modifican su imagen corporal creando una imagen-cuerpo que actúa como transformadora de su mirada sobre su propio cuerpo y que, además, puede mediar en sus relaciones con los demás (especialmente en sus relaciones con el género masculino).

En el análisis no hemos encontrado transformaciones sustantivas en la comprensión que la gente tiene de las relaciones entre privacidad, intimidad y publicidad respecto a si se producen en un espacio físico o virtual, pero sí en la gestión que se hace de ellas y en cómo se llevan a cabo. El espacio social se produce y se define por las relaciones de co-presencia, proximidad y reciprocidad y se elaboran sofisticados patrones culturales sobre ello: quién puede estar en presencia de quien, quién puede ser visto por quien, quién puede tocar o ser tocado por quien; dónde, cuándo y de qué manera. Estas relaciones configuran en gran parte las nociones de espacio público y privado y las relaciones de proximidad y distancia social; la intimidad y la privacidad.

El espacio social es relacional y actuado, y como la identidad, se visibiliza y se materializa de distintos modos, además de que puede ser percibido de forma distinta por los diferentes actores sociales - y según su procedencia étnica, nacional, de clase, de género o de edad. En internet, la co-presencia se gestiona a partir de distintos grados de inclusión y exclusión, mientras que las relaciones de proximidad -íntimas o impersonales- se performan a partir de distintos grados de reciprocidad (Cf. Ben-Ze'ev 2003). El espacio de interacción social puede configurarse como de libre acceso - público-, pero las interacciones que se dan en él pueden ser más o menos próximas o íntimas, sin dejar por ello de ser públicas. Como por ejemplo, el chico que visita el sitio de su novia y le deja un comentario público, o la chica que cuelga una foto íntima en su espacio público para que la vea su novio, o una foto que, aunque es pública, es decir, hecha para 
ser de libre acceso — y dirigida a una amplia audiencia-, por su comentario, vemos claramente que está dedicada al novio.

Lo que hemos visto es que las mujeres entrevistadas van definiendo sobre la marcha lo que es público y privado en términos de limitaciones de acceso, y lo que es íntimo en términos de proximidad o distancia respecto a alguien. En base a los resultados de nuestro análisis, quisiéramos poder afirmar que la producción cultural que realizan estas mujeres es una actividad simbólica que quieren que ocurra y ocurre en la esfera pública-privada que ellas performan y que atañe a la conceptualización social de la persona y de las relaciones entre hombres y mujeres, no solo en la intimidad, en su ámbito privado, sino también como una actuación en el espacio público.

Las imágenes corporales que elaboran no son consideradas por ellas como objetos para ser consumidos de una forma íntima y privada, sino creaciones para ser vistas por una amplia audiencia, y son, en este sentido, productos culturales (se consideren artísticos o no) de pleno derecho. Estas creaciones se pueden apreciar como un ejercicio de visualización de cada mujer en su particularidad, que pretende no sólo ser mirada, sino ser vista "tal y como es", justamente a partir del juego que establece con los estereotipos femeninos, pero también es una forma de incidir activamente en la configuración de las identidades de género y los valores sociales, morales, simbólicos, etc. asociados a la sexualidad. En definitiva, quieren hacerse visibles como creadoras de imágenes; agentes sociales capaces de transformarse a sí mismas y de intervenir en el mundo.

\section{BIBLIOGRAFÍA CITADA}

Ardèvol, E. y A. Vayreda. 2003. "Identidades en línea, prácticas reflexivas", Aportación al Seminario sobre la Identidad en la era digital, en Canarias Mediafest, Las Palmas de Gran Canaria. Disponible en: http://eardevol.files.wordpress.com/2008/10/identidades-en-linea.pdf

Avgitidou, A. 2003. "Performances of the self". Digital Creativity 14 (3): 131-138.

Ben-Ze'ev, A. 2003. "Privacy, emotional closeness and opennes in cyberspace". Computers in Human Behaviour 19: 451-467.

Berger, J. 1972. Ways of seeing. Londres: BBC-Penguin.

Bianciotti, M. C. 2011. "Cuerpo y género: apuntes para pensar prácticas eróticas de mujeres jóvenes. Aportes de Judith Butler y Pierre Bourdieu". Revista Latinoamericana de Estudios sobre Cuerpo, Emociones y Sociedad 6 (3): 70-82.

Butler, J. 2001 [1993]. El género en disputa. México, D.F.: PUEG/UNAM.

Chalfen, R. 1987. Snapshot Versions of Life. Minesota: Bowling Green State University Popular Press.

Coleman, R. 2008. "The Becoming of Bodies. Girls, media effects, and body image". Feminist Media Studies 8 (2): 163-179. 
Dalton, J., N. Lee, A. Goicolea y D. Brown Jr. 2000. "Look At Me: Self-Portrait Photography After Cindy Sherman". PAJ: A Journal of Performance and Art 22 (3): 47-56.

Di Próspero, C. E. 2011. "Autopresentación en Facebook: un yo para el público". Revista Latinoamericana de Estudios sobre Cuerpo, Emociones y Sociedad 6 (3): 44-52.

Enguix B. y E. Ardevol. 2010. "Bodies in Action: performing identity in dating sites", en B. M. Pirani e I. Varga (eds), Acting Bodies and Social Networks: A bridge between technology and Working Memory: 359-370. Lanham: University Press of America.

Esteban, M. L. 2004. Antropología del cuerpo: Género, itinerarios corporales, identidad y cambio. Barcelona: Ediciones Bellaterra.

Featherstone, M. 2010. "Body, Image and Affect in Consumer Culture". Body \& Society 16 (1): 193-221.

Fontcuberta, J. 2010. La cámara de Pandora. La fotografi@ después de la fotografía. Barcelona: Gustavo Gili.

Fontcuberta, J. 2011. A través del espejo. Catálogo. Barcelona: Galería Dels Ángels.

Foucault, M. 1996. Tecnologías del yo y otros textos afines. Barcelona, Buenos Aires, México: Paidós, ICE de la Universidad Autónoma de Barcelona.

Frosh, P. 2001. "The Public Eye and the Citizen-Voyeur: Photography as a Performance of Power". Social Semiotics 11 (1): 43-59.

Harvey, D. 2006. "Space as keyword", en N. Castree y D. Greogory, David Harvey, a critical reader: 271-293. Nueva York: Blackwell.

Giddens, A. 1991. Modernity and self-identity: Self and society in the late modern age. Stanford: Stanford University Press.

Goffman, E. 2004 [1959]. La presentación de la persona en la vida cotidiana. Barcelona: Amorrortu.

Gómez-Cruz, E. y E. Ardèvol. 2011. "Imágenes revueltas: los contextos de la fotografía digital". QuAderns-e 16 (1): 89-102.

Gómez-Cruz, E. 2003. Cibersexo ¿La última frontera del Eros? Un estudio etnográfico. Colima: Universidad de Colima.

Gómez-Cruz, E. 2008. "Imagen pública-privada y ética: Reflexiones desde una investigación etnográfica sobre las prácticas de fotografía digital", en E. Ardèvol, A. Estalella y D. Domínguez (eds.), La mediación tecnológica en la práctica etnogràfica. Simposio del XI Congreso de Antropología. San Sebastián: FAAEE.

Gómez-Cruz, E. 2011. De La Cultura Kodak a la Cultura Flickr. Prácticas de fotografía digital en la vida cotidiana. UOC, Barcelona. Tesis doctoral inédita.

Hjorth, L. 2006. "Snapshots of Almost Contact: Gendered Camera Phone Practices and a Case Study in Seoul, Korea". Cultural Space and Public Sphere in Asia, Seoul:15-16.

Holm, G. 2008. Photography as a Performance. Forum Qualitative Sozialforschung/Forum: Qualitative Social Research 9 (2). URL: http://www.qualitative-research.net/index.php/ fqs/article/viewArticle/ 394/856

Koskinen, I. 2004. Seeing with Mobile Images: Towards Perpetual Visual Contact. Paper presented at the T-Mobile Conference, Hungary.

Koskinen, I. 2005. Mobile Multimedia in Action. Londres: Transaction Pub.

Koskinen, I. 2007. "Managing banality in mobile multimedia", en R. Pertierra (ed.), The social construction and usage of communication technologies: Asian and European experiences: 60-81. Quezon City: University of the Philippines Press. Disponible en: http://dl.acm.org/citation.cfm?id= 1568355

Le Breton, D. 2002. Antropología del cuerpo y modernidad. Madrid: Nueva Visión. 
Lee, D. 2005. "Women's Creation of Camera Phone Culture». Fibreculture Journal 6. Disponible en: http://six.fibreculturejournal.org/fcj-038-womens-creation-of-camera-phoneculture/

Lèvy-Bruhl, L. 1985 [1927]. El alma primitiva. Barcelona: Península.

Lister, M. 1997. La imagen fotográfica en la cultura digital. Barcelona: Paidós Ibérica.

Livingstone, S. 2008. "Taking risky opportunities in youthful content creation: teenagers' use of social networking sites for intimacy, privacy and self-expression". New Media E Society 10 (3): 393.

Martin, R., y J. Spence. 2003. "Photo-Therapy. Psychic realism as a healing art?", en L. Wells (ed.), The photography reader : 402-411. Londres: Routledge.

Martínez-Artero, R. 2004. El retrato: del sujeto en el retrato. Madrid: Editorial Montesinos.

Mitchell, W. 1998. The Reconfigured Eye Visual Truth in the Post-photographic Era. Cambridge, MA: MIT Press.

Mulvey, L. 1975. "Visual pleasure and narrative cinema”. Screen 16 (3): 6

Nunez, C. 2009. "The self portrait, a powerful tool for self-therapy". European Journal of Psychotherapy \& Counselling 11 (1): 51-61.

Okabe, D. y M. Ito. 2003. "Camera phones changing the definition of picture-worthy". Japan Media Review 29.

Palmgren, A. 2009. Today's outfit in Swedish Fashion Weblogs: An ethnographical study of the online body. Paper presented at the 5th European Symposium on Gender \& ICT. Digital Cultures: Participation - Empowerment - Diversity. from http:// elib.suub.uni-bremen.de/ip/docs/00010447.pdf

Ritchin, F. 2008. After Photography. Nueva York: Norton \& Company.

Ritchin, F., S. Dietz y P. Reid. 1999. In Our Own Image. Nueva York: Aperture Foundation, Incorporated.

Rogers, E. M. 2000. "The extensions of men: The correspondence of Marshall McLuhan and Edward T. Hall. Mass Communication and Society 3 (1): 117-135.

Schwarz, O. 2010. "On Friendship, Boobs and the Logic of the Catalogue: Online SelfPortraits as a Means for the Exchange of Capital». Convergence 16 (2): 163.

Sibilia, P. 2008. La intimidad como espectáculo. Buenos Aires: Fondo de Cultura Económica.

San Cornelio Esquerdo, G. 2008. Cartografías de la identidad: seis itinerarios para la reflexión en torno a la práctica artística y comunicativa en la era digital. València: Universitat Politècnica de València.

Slater, D. 1999. Marketing mass photography. Visual culture: the reader. Thousand Oaks: Sage.

Tabachnik, S. 2007. "Retratos secretos. Figuraciones de la identidad en el espacio virtual". Revista Latina de Comunicación Social 62: 1-12.

Thomas, H. y J. Ahmed. 2004. Cultural Bodies; ethnography and theory. Cornwall: Blackwell Publishing.

Thompson, J. 1998. Los media y la modernidad: una teoría de los medios de comunicación. Barcelona: Paidós.

Tinkler, P. 2008. "A fragmented picture: reflections on the photographic practices of young people». Visual Studies 23 (3): 255-266.

Van Dijck, J. 2008. "Digital photography: communication, identity, memory". Visual Communication 7(1): 57-76. 
Wang, Y. 2009. "Posing into being': An exploratory study of Taiwanese girls selfportraiture online", en N. Carpentier, P. Pruulmann-Vengerfeldt, R. Kilborn y otros (eds.), Communicative Approaches to Politics and Ethics in Europe. Tartu University Press.

Wenger, E. 1999. Communities of practice: Learning, meaning, and identity. Cambridge: Cambridge University Press.

Fecha de recepción: 4 de noviembre de 2011

Fecha de aceptación: 27 de marzo de 2012 